Check for updates

Cite this: Chem. Sci., 2019, 10, 6503

๑ All publication charges for this article have been paid for by the Royal Society of Chemistry

Received 29th January 2019

Accepted 22nd May 2019

DOI: $10.1039 / \mathrm{c} 9 \mathrm{sc} 00531 \mathrm{e}$

rsc.li/chemical-science

\section{Residue-specific identification of phase separation hot spots of Alzheimer's-related protein tau $\uparrow$}

\author{
Susmitha Ambadipudi, ${ }^{a}$ Jithender G. Reddy, ${ }^{\text {bc }}$ Jacek Biernat, ${ }^{d}$ Eckhard Mandelkow ${ }^{\text {de }}$ \\ and Markus Zweckstetter (iD *ab
}

\begin{abstract}
Liquid-liquid phase separation (LLPS) of proteins enables the formation of non-membrane-bound organelles in cells and is associated with cancer and neurodegeneration. Little is known however about the structure and dynamics of proteins in LLPS conditions, because of the polymorphic nature of liquidlike protein droplets. Using carbon-detected NMR experiments we here show that the conversion of the aggregation-prone repeat region of the Alzheimer's-related protein tau from the dispersed monomeric state to phase-separated liquid-like droplets involves tau's aggregation-prone hexapeptides and regulatory KXGS motifs. Droplet dissolution in presence of 1,6-hexanediol revealed that chemical shift perturbations in the hexapeptide motifs are temperature driven, while those in KXGS motifs report on phase separation. Residue-specific secondary structure analysis further indicated that tau's repeat region exists in extended conformation in the dispersed state and attains transient $\beta$-hairpin propensity upon LLPS. Taken together our work shows that NMR spectroscopy can provide high-resolution insights into LLPS-induced changes in intrinsically disordered proteins.
\end{abstract}

\section{Introduction}

In living cells, biochemical reactions are functionally optimized and occur in both membrane-bound (e.g. mitochondria, Golgi) and non-membrane-bound organelles (e.g. nucleoli, stress granules). ${ }^{1,2}$ Non-membrane-bound organelles are formed by liquid-liquid phase separation (LLPS) of intrinsically disordered proteins and protein regions and are involved in cell signaling and nucleic acid metabolism..$^{1,3,4}$ Aberrant phase separation has been linked to protein condensation diseases such as neurodegeneration and cancer., ${ }^{5,6}$ For example, the proteins Fused in Sarcoma (FUS; associated with amyotrophic lateral sclerosis) and tau protein (associated with Alzheimer's disease and tauopathies) undergo LLPS and form liquid-like droplets in solution. ${ }^{7-12}$ The composition and biophysical environment in the interior of phase separated protein droplets is distinct from the surrounding aqueous environment., ${ }^{2,134}$

${ }^{a}$ Deutsches Zentrum für Neurodegenerative Erkrankungen (DZNE), Von-Siebold-Str. 3a, 37075 Göttingen, Germany. E-mail: mazw@nmr.mpibpc.mpg.de

${ }^{b}$ Max-Planck-Institut für Biophysikalische Chemie, Am Fassberg 11, 37077 Göttingen, Germany

'NMR \& Structural Chemistry Division, CSIR-Indian Institute of Chemical Technology, Hyderabad, 500007, India

${ }^{d}$ Deutsches Zentrum für Neurodegenerative Erkrankungen (DZNE), Ludwig-ErhardAllee 2, 53175 Bonn, Germany

${ }^{e}$ CAESAR Research Center, Bonn, MPI for Metabolism Research, Hamburg Outstation, 22607 Hamburg, Germany

$\dagger$ Electronic supplementary information (ESI) available. See DOI: 10.1039/c9sc00531e
NMR spectroscopy is a versatile tool to study the structural propensities of disordered proteins. Because of the dynamic and polymorphic nature of liquid-like protein droplets, however, the atomistic details and local structural preferences of intrinsically disordered proteins within liquid-like droplets remain largely elusive.

Pathogenic aggregation of the microtubule-associated protein tau is the hallmark of Alzheimer's disease and tauopathies. ${ }^{15,16}$ The 441-residue tau is the longest isoform in the adult human brain and comprises two N-terminal inserts, the proline-rich region and four pseudo-repeats in the C-terminal half. ${ }^{17-20}$ The four pseudo-repeats are important for microtubule-binding and aggregation. ${ }^{21} \mathrm{~A}$ truncated tau version that contains only the four pseudo-repeats (termed K18) has higher aggregation propensity than the full-length protein. ${ }^{22}$ We and others previously showed that both tau and K18 undergo LLPS in a $\mathrm{pH}$ - and temperature-dependent manner, droplet formation is modulated by phosphorylation at KXGS motifs and LLPS promotes tau fibrillization and microtubule polymerization. ${ }^{10-12,23}$

Here, we used ${ }^{13} \mathrm{C}$-detected NMR experiments to identify the key residues involved in phase separation of the fourrepeat region of tau at high resolution. We show that the local chemical environment at tau's aggregation-prone hexapeptides and the regulatory KXGS motifs is altered upon phase separation and droplet formation. Residue stretches spanning these motifs gain transient $\beta$-hairpin propensity, while the protein retains the overall disordered nature upon LLPS. 


\section{Results and discussion}

Previous studies showed that K18 undergoes self-coacervation, i.e. phase separation in the absence of co-factors or molecular crowding agents, at $100 \mu \mathrm{M}$ protein concentration, $37^{\circ} \mathrm{C}, \mathrm{pH}$ 8.8. K18 droplets form in a temperature-dependent, reversible manner and are liquid-like and dynamic. ${ }^{\mathbf{1 0}}$ Two-dimensional (2D) ${ }^{1} \mathrm{H} /{ }^{15} \mathrm{~N}$ NMR correlation spectra of K18 in the monomeric dispersed state at $5{ }^{\circ} \mathrm{C}$ and the phase separated state at $37{ }^{\circ} \mathrm{C}$ displayed poor signal dispersion (Fig. 1a). In addition, the ${ }^{1} \mathrm{H} /{ }^{15} \mathrm{~N}$ NMR signals were broadened at $37{ }^{\circ} \mathrm{C}$ and $\mathrm{pH} 8.8$ (Fig. 1a). LLPS-induced broadening of tau's NMR signals might be attributed to the conditions of high $\mathrm{pH}$ and physiological temperature, which favor rapid exchange of labile amide protons with deuterium atoms of the buffer. To exclude contributions from rapid solvent exchange to NMR signal attenuation, we separated the protein sample from $\mathrm{D}_{2} \mathrm{O}$, which is used for field-to-frequency lock during NMR measurements. To this end, a $\mathrm{D}_{2} \mathrm{O}$-containing capillary was placed into the NMR sample tube, which contained protein in $\mathrm{H}_{2} \mathrm{O}$ solvent (Fig. 1a, insert). ${ }^{1} \mathrm{H} /{ }^{15} \mathrm{~N}$ correlation spectra were then recorded for increasing temperatures from $5{ }^{\circ} \mathrm{C}$ to $37{ }^{\circ} \mathrm{C}$ (Fig. 1a and $\mathrm{S} 1 \mathrm{a} \dagger$ ). Droplet formation was confirmed by differential interference contrast (DIC) microscopy (Fig. 1d). Fluorescence microscopy of droplets using Alexa 488 labeled protein showed that the concentration of K18 within the droplets is $\sim 20-25$-fold higher than in the surrounding environment (Fig. S2 $\dagger$ ).

The NMR spectra displayed temperature-dependent chemical shift changes with signal broadening varying across residues. Several of the ${ }^{1} \mathrm{H} /{ }^{15} \mathrm{~N}$ signals became undetectable above $25{ }^{\circ} \mathrm{C}$ (Fig. S1a and $\mathrm{b} \dagger$ ). The experiments showed that LLPS of K18 induces - independent of rapid solvent exchange - strong NMR signal broadening in ${ }^{1} \mathrm{H} /{ }^{15} \mathrm{~N}$ correlation spectra. Because little signal broadening was observed in ${ }^{1} \mathrm{H} /{ }^{13} \mathrm{C}$ HSQC spectra of phase-separated $\mathrm{K} 18$ recorded under identical solution conditions, ${ }^{10}$ inhomogeneity in magnetic susceptibility anisotropy can be excluded as a major source of broadening. Instead, chemical exchange between different conformations (potentially involving transient hydrogen bonds) might cause line broadening of ${ }^{1} \mathrm{H} /{ }^{15} \mathrm{~N}$ cross peaks. Consistent with the LLPSspecific nature of NMR signal broadening, other intrinsically disordered proteins showed severe broadening in ${ }^{1} \mathrm{H} /{ }^{15} \mathrm{~N}$ correlation spectra upon LLPS. ${ }^{7,24}$

In order to improve spectral resolution and minimize LLPSinduced NMR signal broadening in $\mathrm{K} 18$, we recorded $2 \mathrm{D}{ }^{13} \mathrm{C}$ detected NMR experiments. ${ }^{25}{ }^{13} \mathrm{CO} /{ }^{15} \mathrm{~N}$ correlation spectra (CON) are particularly powerful, because the chemical shift dispersion of $\mathrm{CO}$ is larger when compared to $\mathrm{H}^{\mathrm{N}}$ and therefore

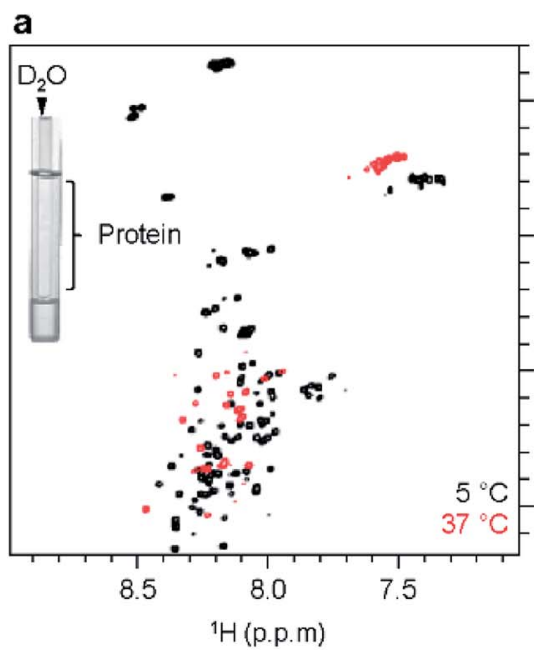

b c
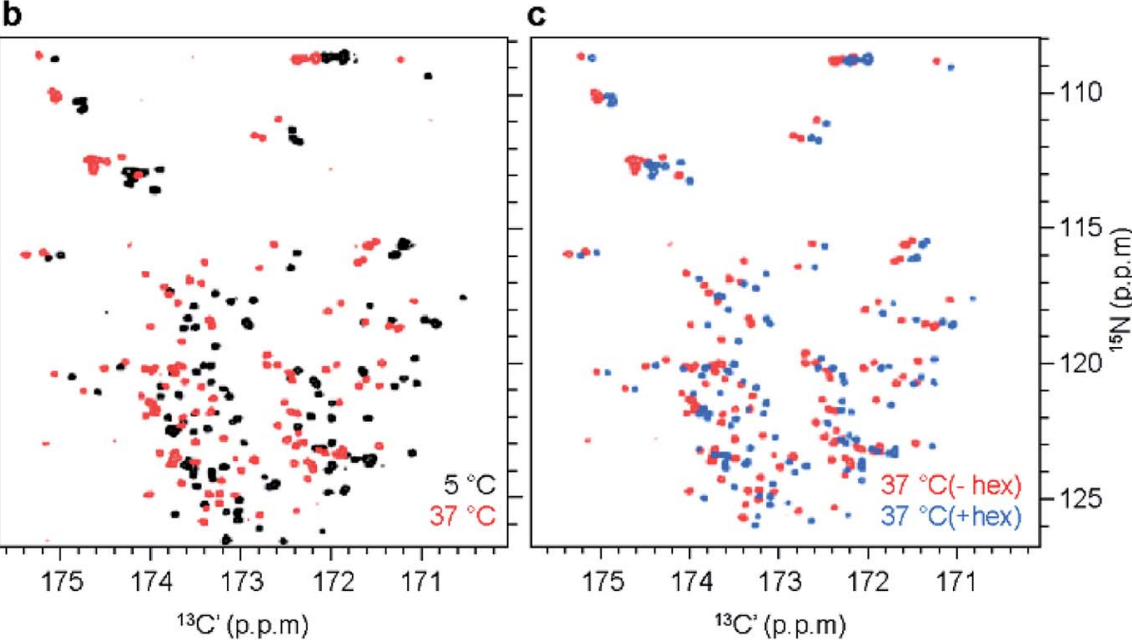

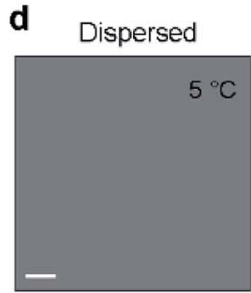

Scale: $10 \mu \mathrm{m}$ e

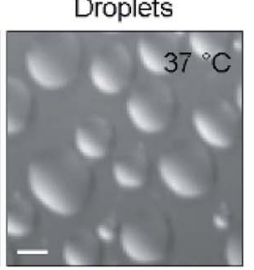

+1,6-hexanediol

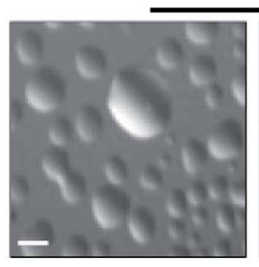

$0 \mathrm{~min}$
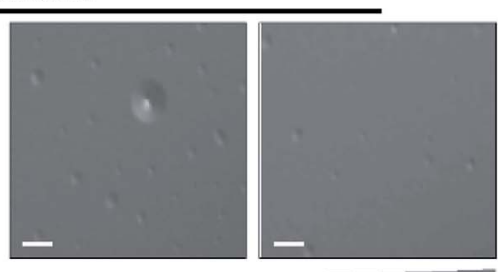

2 min

Fig. 1 NMR spectroscopy of liquid-liquid phase separation of the repeat domain of tau. (a and b) Superposition of $2 \mathrm{D}{ }^{1} \mathrm{H} /{ }^{15} \mathrm{~N}-\mathrm{HSQC}(\mathrm{a})$ and $2 \mathrm{D}$ CON (b) spectra of $\mathrm{K} 18$ in the monomeric dispersed state $\left(5^{\circ} \mathrm{C}\right.$, black) and the droplet phase $\left(37^{\circ} \mathrm{C}\right.$, red). To avoid contributions of solvent exchange to NMR signal broadening in ${ }^{1} \mathrm{H} /{ }^{15} \mathrm{~N}$ correlation spectra, $\mathrm{D}_{2} \mathrm{O}$ was placed into a separate capillary tube (insert in a). (c) Superposition of $\mathrm{CON}$ spectra of $\mathrm{K} 18$ recorded at $37^{\circ} \mathrm{C}$ in the absence (-hex, red) and presence (+hex, blue) of $3 \% 1,6$-hexanediol, which rapidly dissolved K18 droplets (e). (d) DIC microscopy demonstrates K18 droplet formation at $37^{\circ} \mathrm{C}$. (e) Time-dependent dissolution of K18 droplets in presence of $3 \%$ 1,6-hexanediol observed by DIC microscopy. 
CON spectra offer better spectral resolution (Fig. 1b and S1c $\dagger)^{26,27}$ In addition, CON cross-peaks are less affected by solvent exchange at high $\mathrm{pH}$ and temperature.$^{25} \mathrm{CON}$ spectra of K18 were recorded in both the monomeric dispersed $\left(5^{\circ} \mathrm{C}\right)$ and phase-separated state $\left(37{ }^{\circ} \mathrm{C}\right)$, keeping sample conditions identical to those used for ${ }^{1} \mathrm{H} /{ }^{15} \mathrm{~N}$ correlation spectra. Both CON spectra were well-resolved, showed little signal broadening and displayed chemical shift perturbations between $5{ }^{\circ} \mathrm{C}$ and $37^{\circ} \mathrm{C}$ (Fig. 1b, S1c and di).

We next asked if the chemical shift changes inherent to temperature changes can be distinguished from those due to LLPS. To this end, we added 1,6-hexanediol, an aliphatic alcohol, to $\mathrm{K} 18$ droplets preformed at $37{ }^{\circ} \mathrm{C}$. 1,6-hexanediol dissolves liquid-like droplets in vitro and in cells through disruption of weak interactions between the constituent protein molecules. ${ }^{28}$ DIC microscopy demonstrated that addition of $3 \%$ 1,6-hexanediol dissolved K18 droplets within $\sim 2$ minutes (Fig. 1e). Superposition of CON spectra in the phase-separated $\left(37^{\circ} \mathrm{C}\right.$, without 1,6-hexanediol) and droplet-dissolved states $\left(37^{\circ} \mathrm{C}\right.$, with 1,6-hexanediol) revealed small chemical shift changes (Fig. 1c), suggesting that the two states differ locally in structure and/or dynamics.

The high quality of the ${ }^{13} \mathrm{C}$-detected NMR experiments at $37^{\circ} \mathrm{C}$ suggested that it might be possible to follow the chemical shift perturbations for individual residues, and thus gain residue-specific insights into K18 phase separation. To this end, we assigned the backbone resonances of $\mathrm{K} 18$ at $5{ }^{\circ} \mathrm{C}$ and $\mathrm{pH} 8.8$, with the help of $\mathrm{HNCO},{ }^{29} \mathrm{HN}(\mathrm{C}) \mathrm{N},{ }^{30} \mathrm{HNCACB}$ and $\mathrm{HN}(\mathrm{CO})$ $\mathrm{CACB}^{31}$ experiments (Table $\left.\mathrm{S} 1 \dagger\right)$. The observed chemical shifts were used to assign the peaks (including proline residues) in the CON spectrum at $5{ }^{\circ} \mathrm{C}$. We then recorded a series of CON spectra for increasing temperatures from 5 to $37{ }^{\circ} \mathrm{C}$. High spectral quality was retained for all temperatures (Fig. S1c and d广), in contrast to ${ }^{1} \mathrm{H} /{ }^{15} \mathrm{~N}$ correlation spectra, where broadening of NMR signals was severe in conditions of LLPS $\left(37^{\circ} \mathrm{C}\right)$ (Fig. S1a and $b \dagger$ ). Many of the NMR signals that were broadened beyond detection in the ${ }^{1} \mathrm{H} /{ }^{15} \mathrm{~N}$ spectra (Fig. S1b †) were from glycine and serine residues (Fig. S1d †). Subsequently, CON spectra at increasing temperatures were sequence-specifically assigned (including prolines) based on the resonance assignment at $5{ }^{\circ} \mathrm{C}$.

As the dispersed protein proceeded to form droplets when reaching $37^{\circ} \mathrm{C}$, chemical shift perturbation was observed for most K18 residues (Fig. 1b, S1c and d广). Analysis of the perturbations for individual nuclei furthermore showed that $\mathrm{CO}$ and $\mathrm{N}$ display a distinct sequence behavior. In case of $\mathrm{CO}$, the perturbations are larger in proximity to the KXGS motifs, while for $\mathrm{N}$ the perturbation was most pronounced at the hexapeptides (Fig. 2a and b). In presence of 1,6-hexanediol, where the droplets were dissolved, the perturbation (relative to $5{ }^{\circ} \mathrm{C}$ ) in the hexapeptides was retained, reflecting that these changes are primarily caused by the change in temperature from 5 to $37^{\circ} \mathrm{C}$ (Fig. 2c). 1,6-hexanediol showed little or no effect on the chemical shifts of the dispersed protein at $5{ }^{\circ} \mathrm{C}$ (Fig. S3†). The combined chemical shift difference plot with and without 1,6hexanediol (i.e. droplets dissolved vs. K18 droplets at $37^{\circ} \mathrm{C}$ ) displayed perturbation in the KXGS motifs of K18 (Fig. $2 \mathrm{~d}$ and $\mathrm{S} 4 \dagger)$. In addition, the proline-rich region and the PGGG motif in a
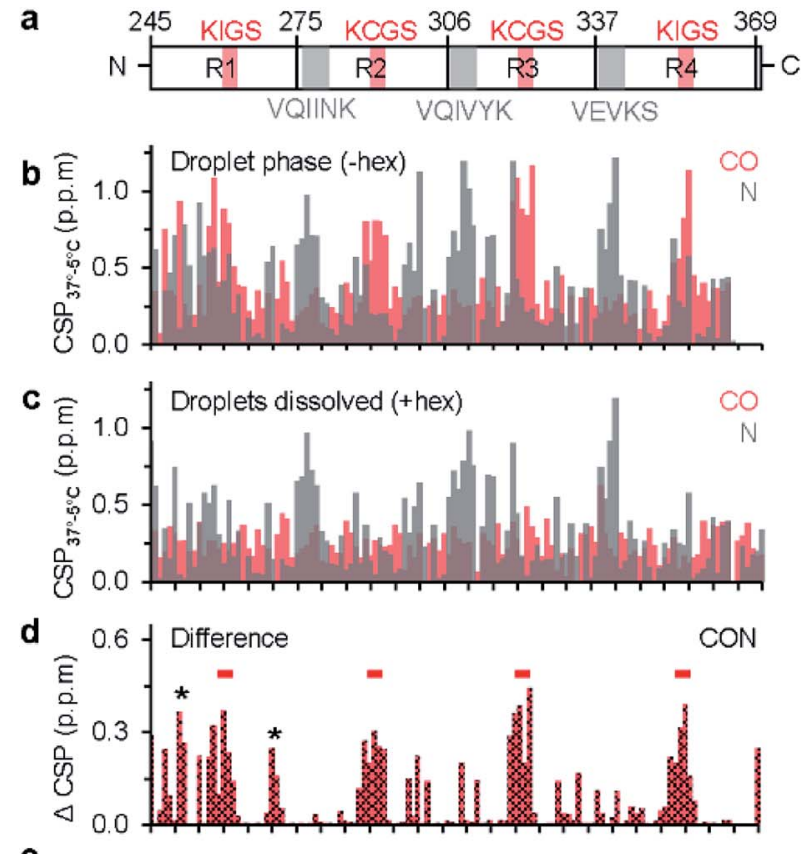

e

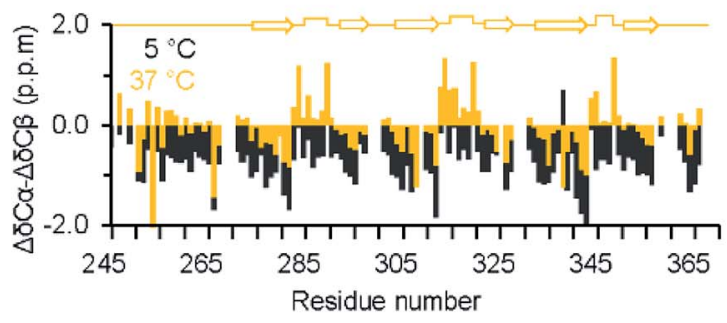

Fig. 2 Residue-specific analysis of LLPS-induced changes in chemical environment and local structure in the repeat-region of tau. (a) Domain representation of K18. Pseudo-repeats are shown as R1-R4, hexapeptides are marked in grey, KXGS motifs in red. (b) Chemical shift perturbation (CSP) of $\mathrm{CO}$ (red) and $\mathrm{N}$ (grey) from the dispersed monomeric $\left(5^{\circ} \mathrm{C}\right)$ to the droplet state $\left(37^{\circ} \mathrm{C}\right)$. (c) CSP of $\mathrm{CO}$ and $\mathrm{N}$ from the dispersed monomeric state $\left(5^{\circ} \mathrm{C}\right)$ to the dispersed monomeric state at $37^{\circ} \mathrm{C}$ (i.e. in the presence of 1,6-hexanediol), revealing temperature-induced changes in N chemical shifts. (d) Averaged CSP $(\Delta \mathrm{CSP})$ of $\mathrm{CO}$ and $\mathrm{N}$ in $\mathrm{K} 18$ between the droplets state (without 1,6hexanediol at $37^{\circ} \mathrm{C}$ ) and after droplet dissolution (with 1,6-hexanediol at $37^{\circ} \mathrm{C}$ ). The four KXGS motifs (red bars), as well as the proline-rich region and the PGGG motif (asterisk) in R1 display pronounced $\triangle \mathrm{CSP}$. (e) Secondary structure propensity of K18 in the monomeric dispersed state at $5{ }^{\circ} \mathrm{C}$ (black) and the LLPS-phase at $37^{\circ} \mathrm{C}$ (yellow). At $37^{\circ} \mathrm{C}$, secondary chemical shifts suggest the presence of $\beta$-hairpin-like conformations in repeats R2, R3 and R4 (illustrated by a cartoon diagram on top).

repeat R1 were affected by LLPS (Fig. 2d). Consistent with the importance of the KXGS motifs for tau-LLPS, phosphorylation of serine residues in the KXGS motifs by MARK2, a kinase that is involved in regulation of microtubule binding of tau, ${ }^{32}$ promotes self-coacervation of tau. ${ }^{10,12}$

We further asked if the changes in chemical shift environment concomitantly induced local structural changes upon LLPS of K18. Our previous study based on amide $\mathrm{H}$ and $\mathrm{N}$ chemical shift dispersion and far UV circular dichroism of K18 at $37^{\circ} \mathrm{C}$ suggested that the protein remains largely disordered within the droplets, in agreement with the intrinsically 
disordered nature of tau. ${ }^{\mathbf{1 0}}$ However, these approaches did not allow a residue-specific analysis of the structural content in the phase-separated state. We therefore recorded $2 \mathrm{D}{ }^{13} \mathrm{C}$-detected CBCACO spectra $^{25}$ of $\mathrm{K} 18$ for increasing temperatures from $5{ }^{\circ} \mathrm{C}$ (dispersed state) to $37{ }^{\circ} \mathrm{C}$ (droplet state) (Fig. S5 $\dagger$ ). Because $\mathrm{CA}, \mathrm{CB}$ and $\mathrm{CO}$ chemical shifts are sensitive to phi/psi dihedral angles, secondary chemical shifts $(\Delta \delta)$, estimated as the difference between observed and random coil chemical shift values, report on protein secondary structure with positive (negative) deviation of $\Delta \delta \mathrm{CA}$ and $\Delta \delta \mathrm{CO}$ indicating helical ( $\beta$-structure) propensity.

First, the CBCACO spectrum at $5{ }^{\circ} \mathrm{C}$ was assigned using the assignment obtained at $5{ }^{\circ} \mathrm{C}$ by ${ }^{1} \mathrm{H}$-detected experiments (see above). Next, this assignment was used to follow the temperature-dependent chemical shift changes of $\mathrm{CA}, \mathrm{CB}$ and CO resonances from $5{ }^{\circ} \mathrm{C}$ to $37^{\circ} \mathrm{C}$. Subsequently, temperaturedependent $\Delta \delta$ values of $\mathrm{CA}, \mathrm{CB}$ and $\mathrm{CO}$ were estimated using random coil chemical shifts at $\mathrm{pH} 8.8$ and the given temperature. ${ }^{33}$ At $5{ }^{\circ} \mathrm{C}$, the secondary structural propensity, calculated as $\Delta \delta \mathrm{CA}-\Delta \delta \mathrm{CB}$ was negative for almost all residues (Fig. 2e), suggesting an extended K18 conformation. Upon phase separation at $37{ }^{\circ} \mathrm{C}$, V275-H299, S305-H330 and G334-I360, which include the hexapeptides and KXGS motifs, displayed an alternating negative/positive $\Delta \delta \mathrm{CA}-\Delta \delta \mathrm{CB}$ pattern, as expected for $\beta$-hairpin structure (Fig. 2e). A similar trend was observed for CO secondary chemical shifts at $37^{\circ} \mathrm{C}$, in the absence of 1,6hexanediol (Fig. S6a $\dagger$ ). In presence of 1,6-hexanediol where the droplets were dissolved, more negative CO secondary chemical shifts were observed, indicating a higher tendency for extended structure (Fig. S6b $\dagger$ ). In the pseudo-repeats R2 and R3, ' $\mathrm{X}$ ' of the KXGS motif corresponds to C291 and C322, respectively. The observed CB chemical shifts of C291 (28.47 ppm) and C322 $(28.48 \mathrm{ppm})$ are characteristic for a reduced thiol group. ${ }^{34}$ Protein dimerization as a source for the observed changes in secondary structure propensity could therefore be excluded.

A defining property of intrinsically disordered proteins is that they can rapidly exchange between different conformations in solution. ${ }^{35}$ In this situation, the magnitude of $\Delta \delta$ will be reduced when compared to well-ordered proteins. In conditions of LLPS, the protein also can exchange between the droplet interior and the surrounding environment, potentially resulting in further chemical shift averaging (when the exchange is fast on the NMR time scale). The small changes in secondary structure propensity that were observed for K18 upon LLPS (Fig. 2e) are thus in agreement with the dynamic and polymorphic nature of phase separation of intrinsically disordered proteins. The propensity for $\beta$-hairpin formation in repeats 2,3 and 4 upon LLPS suggests that LLPS favors amyloid promoting structure of tau. Conversion of liquid-like droplets into hydrogels might further stabilize the transient $\beta$-hairpin conformation and result in cross- $\beta$-structure in amyloid fibrils as previously observed for FUS protein. ${ }^{36}$

\section{Conclusions}

In conclusion, we provided residue-specific insights into liquidliquid phase separation of the repeat region of tau. We identified hot spots of LLPS and showed that the aggregationprone hexapeptides and KXGS motifs are important for droplet formation. Our study further demonstrates that ${ }^{13} \mathrm{C}$ detected NMR spectroscopy is a powerful approach to study liquid-liquid phase separation of intrinsically disordered proteins.

\section{Experimental section}

\section{Sample preparation}

${ }^{13} \mathrm{C} /{ }^{15} \mathrm{~N}$-labelled $\mathrm{K} 18$ was recombinantly expressed in $E$. coli BL21(DE3) cells and purified according to published protocols. ${ }^{21,22}$ Typically, samples contained $100 \mu \mathrm{M}$ of protein in $50 \mathrm{mM}$ sodium phosphate $(\mathrm{pH} 8.8), 100 \mu \mathrm{M}$ of tris(2carboxyethyl)phosphine and $0.02 \%$ sodium azide. For NMR measurements, $50 \mu \mathrm{M}$ of 4,4-dimethyl-4-silapentane-1-sulfonic acid was added for chemical shift referencing.

\section{DIC and fluorescence microscopy}

Droplet formation was monitored by DIC microscopy. For quantification, protein was fluorescently labelled with Alexa 488 using Alexa Fluor 488 microscale protein labelling kit (Thermo Fisher Scientific, A30006). Unlabelled and Alexa-488 labelled proteins were mixed in a ratio of $40: 1$. DIC and fluorescent images were acquired on a DM6000B (Leica) microscope with a $63 \times$-objective (water immersion). Relative protein concentrations in droplets and the surrounding environment were estimated from fluorescence intensities. $15 \mu \mathrm{l}$ of protein sample was mixed with 7\% v/v polyethylene glycol (PEG-3350) and loaded onto a microscope slide with single concavity. For droplet dissolution, $3 \%$ of 1,6-hexanediol was added to preformed K18 droplets. Images were acquired every 10 seconds until droplet dissolution was observed. Images were processed using ImageJ.

\section{NMR spectroscopy}

NMR spectra were recorded on a Bruker $700 \mathrm{MHz}$ spectrometer equipped with a triple resonance cryogenic probe. To avoid solvent exchange effects, protein sample (prepared in $\mathrm{H}_{2} \mathrm{O}$ solvent) and $\mathrm{D}_{2} \mathrm{O}$ were separately loaded into a $5 \mathrm{~mm}$ Shigemi and a $1.7 \mathrm{~mm}$ capillary tube, respectively. The sample was degassed and the tubes were concentrically sealed. For temperature-dependent measurements, the sample was incubated for 20-24 $\mathrm{h}$ prior to acquisition at the respective temperature. ${ }^{1} \mathrm{H} /{ }^{15} \mathrm{~N}$ HSQC spectra were acquired with 200 increments (8 scans per increment) and an inter-scan delay of 1 s. $2 \mathrm{D}$ CON and 2D CBCACO experiments were acquired with 1024 and 128 complex points in the direct and indirect dimension, respectively, with 48/128 scans per increment (CON/ CBCACO). The inter-scan delay was set to $1 \mathrm{~s}$. NMR spectra were processed using Bruker Topspin 3.5 and analysed in CARA. ${ }^{37}$ Chemical shift perturbation (CSP) of individual nuclei was plotted as $\Delta \delta \mathrm{CO}$ and $\Delta \delta \mathrm{N}$, with $\Delta \delta \mathrm{CO}=\delta \mathrm{CO}_{37^{\circ} \mathrm{C}}-\delta \mathrm{CO}_{5^{\circ} \mathrm{C}}$ and $\Delta \delta \mathrm{N}=\delta \mathrm{N}_{37^{\circ} \mathrm{C}}-\delta \mathrm{N}_{5^{\circ} \mathrm{C}}$. Averaged CSPs were calculated as $\Delta \mathrm{CSP}$ $=\sqrt{ } 0.3 \times(\Delta \delta \mathrm{CO})^{2}+0.14(\Delta \delta \mathrm{N})^{2}$. Secondary chemical shifts were calculated as $\Delta \delta=\Delta \delta_{\text {observed }}-\Delta \delta_{\text {random coil }}$. 


\section{Conflicts of interest}

The authors declare no conflict of interest.

\section{Acknowledgements}

M. Z. was supported by the advanced grant '787679 - LLPS-NMR' of the European Research Council.

\section{Notes and references}

1 D. M. Mitrea and R. W. Kriwacki, Cell Commun. Signaling, 2016, 14, 1.

2 A. A. Hyman, C. A. Weber and F. Julicher, Annu. Rev. Cell Dev. Biol., 2014, 30, 39-58.

3 Y. Lin, D. S. Protter, M. K. Rosen and R. Parker, Mol. Cell, 2015, 60, 208-219.

4 P. A. Chong and J. D. Forman-Kay, Curr. Opin. Struct. Biol., 2016, 41, 180-186.

5 M. Ramaswami, J. P. Taylor and R. Parker, Cell, 2013, 154, 727-736.

6 A. Aguzzi and M. Altmeyer, Trends Cell Biol., 2016, 26, 547558.

7 K. A. Burke, A. M. Janke, C. L. Rhine and N. L. Fawzi, Mol. Cell, 2015, 60, 231-241.

8 T. Murakami, S. Qamar, J. Q. Lin, G. S. Schierle, E. Rees, A. Miyashita, A. R. Costa, R. B. Dodd, F. T. Chan, C. H. Michel, D. Kronenberg-Versteeg, Y. Li, S. P. Yang, Y. Wakutani, W. Meadows, R. R. Ferry, L. Dong, G. G. Tartaglia, G. Favrin, W. L. Lin, D. W. Dickson, M. Zhen, D. Ron, G. Schmitt-Ulms, P. E. Fraser, N. A. Shneider, C. Holt, M. Vendruscolo, C. F. Kaminski and P. St George-Hyslop, Neuron, 2015, 88, 678-690.

9 A. Patel, H. O. Lee, L. Jawerth, S. Maharana, M. Jahnel, M. Y. Hein, S. Stoynov, J. Mahamid, S. Saha, T. M. Franzmann, A. Pozniakovski, I. Poser, N. Maghelli, L. A. Royer, M. Weigert, E. W. Myers, S. Grill, D. Drechsel, A. A. Hyman and S. Alberti, Cell, 2015, 162, 1066-1077.

10 S. Ambadipudi, J. Biernat, D. Riedel, E. Mandelkow and M. Zweckstetter, Nat. Commun., 2017, 8, 275.

11 X. Zhang, Y. Lin, N. A. Eschmann, H. Zhou, J. N. Rauch, I. Hernandez, E. Guzman, K. S. Kosik and S. Han, PLoS Biol., 2017, 15, e2002183.

12 S. Wegmann, B. Eftekharzadeh, K. Tepper, K. M. Zoltowska, R. E. Bennett, S. Dujardin, P. R. Laskowski, D. MacKenzie, T. Kamath, C. Commins, C. Vanderburg, A. D. Roe, Z. Fan, A. M. Molliex, A. Hernandez-Vega, D. Muller, A. A. Hyman, E. Mandelkow, J. P. Taylor and B. T. Hyman, EMBO J., 2018, 37, e98049.

13 T. J. Nott, T. D. Craggs and A. J. Baldwin, Nat. Chem., 2016, 8, 569-575.

14 A. A. Hyman and C. P. Brangwynne, Dev. Cell, 2011, 21, 1416.
15 C. Ballatore, V. M. Lee and J. Q. Trojanowski, Nat. Rev. Neurosci., 2007, 8, 663-672.

16 C. Bancher, H. Braak, P. Fischer and K. A. Jellinger, Neurosci. Lett., 1993, 162, 179-182.

17 M. D. Weingarten, A. H. Lockwood, S. Y. Hwo and M. W. Kirschner, Proc. Natl. Acad. Sci. U. S. A., 1975, 72, 1858-1862.

18 M. Goedert, M. G. Spillantini, R. Jakes, D. Rutherford and R. A. Crowther, Neuron, 1989, 3, 519-526.

19 K. A. Butner and M. W. Kirschner, J. Cell Biol., 1991, 115, 717-730.

20 N. Gustke, B. Trinczek, J. Biernat, E. M. Mandelkow and E. Mandelkow, Biochemistry, 1994, 33, 9511-9522.

21 M. D. Mukrasch, J. Biernat, M. von Bergen, C. Griesinger, E. Mandelkow and M. Zweckstetter, J. Biol. Chem., 2005, 280, 24978-24986.

22 H. Wille, G. Drewes, J. Biernat, E. M. Mandelkow and E. Mandelkow, J. Cell Biol., 1992, 118, 573-584.

23 A. Hernandez-Vega, M. Braun, L. Scharrel, M. Jahnel, S. Wegmann, B. T. Hyman, S. Alberti, S. Diez and A. A. Hyman, Cell Rep., 2017, 20, 2304-2312.

24 J. P. Brady, P. J. Farber, A. Sekhar, Y. H. Lin, R. Huang, A. Bah, T. J. Nott, H. S. Chan, A. J. Baldwin, J. D. FormanKay and L. E. Kay, Proc. Natl. Acad. Sci. U. S. A., 2017, 114, E8194-E8203.

25 I. C. Felli, L. Gonnelli and R. Pierattelli, Nat. Protoc., 2014, 9, 2005-2016.

26 L. Duma, S. Hediger, A. Lesage and L. Emsley, J. Magn. Reson., 2003, 164, 187-195.

27 W. Bermel, I. Bertini, L. Duma, I. C. Felli, L. Emsley, R. Pierattelli and P. R. Vasos, Angew. Chem., 2005, 44, 3089-3092.

28 S. Kroschwald, S. Maharana, D. Mateju, L. Malinovska, E. Nuske, I. Poser, D. Richter and S. Alberti, eLife, 2015, 4, e06807.

29 M. J. Blackledge, R. Bruschweiler, C. Griesinger, J. M. Schmidt, P. Xu and R. R. Ernst, Biochemistry, 1993, 32, 10960-10974.

30 S. C. Panchal, N. S. Bhavesh and R. V. Hosur, J. Biomol. NMR, 2001, 20, 135-147.

31 A. Yamazaki, S. Kaya, T. Tsuda, Y. Araki, Y. Hayashi and K. Taniguchi, J. Biochem., 1994, 116, 1360-1369.

32 J. Biernat, N. Gustke, G. Drewes, E. M. Mandelkow and E. Mandelkow, Neuron, 1993, 11, 153-163.

33 M. Kjaergaard and F. M. Poulsen, J. Biomol. NMR, 2011, 50, 157-165.

34 O. A. Martin, M. E. Villegas, J. A. Vila and H. A. Scheraga, J. Biomol. NMR, 2010, 46, 217-225.

35 K. Tamiola, B. Acar and F. A. Mulder, J. Am. Chem. Soc., 2010, 132, 18000-18003.

36 D. T. Murray, M. Kato, Y. Lin, K. R. Thurber, I. Hung, S. L. McKnight and R. Tycko, Cell, 2017, 171, 615-627.

37 R. Keller, 2004, http:/www.cara.ethz.ch/Wiki/FrontPage. 